REFERENCES AND/OR ACKNOWLEDGEMENTS

1. Rugo HS, et al. Lancet Oncol 2017;18:654-662.

No conflict of interest.

\section{PC-041 SURFACE CONTAMINATION WITH CYTOTOXIC DRUGS IN EUROPEAN HOSPITAL WARDS}

${ }^{1} \mathrm{E}$ Korczowska*, ${ }^{1} \mathrm{H}$ Jankowiak-Gracz, ${ }^{2} \mathrm{M}$ Crul, ${ }^{3}$ J Tuerk, ${ }^{4} \mathrm{D}$ Arnold, ${ }^{5} \mathrm{~K}$ Meier. ${ }^{1}$ University Hospital of Lord's Transfiguration, Hospital Pharmacy, Poznan, Poland; ${ }^{2}$ Amsterdam University Medical Centre, Department of Clinical Pharmacology and Pharmacy, Amsterdam, The Netherlands; ${ }^{3}$ Institute of Energy and Environmental Technology, luta, Duisburg, Germany; ${ }^{4}$ Department of Medical Oncology, Klinik Für Tumorbiologie, Freiburg, Germany; 5 Institute For Applied Healthcare Sciences, Ifahs, Hamburg, Germany

\subsection{6/ejhpharm-2020-eahpconf.88}

Background and importance Several studies have shown that antineoplastic drug contamination is found on various work surfaces in hospitals and varies widely on wards. The MASHA project (research about environmental contamination by cytotoxics and management of safe handling procedures) was to set up to conduct new research, in cooperation with the European Society for Medical Oncology, into contamination levels in hospital wards.

Aim and objectives To obtain an overview of the current levels of cytotoxic contamination in European hospital wards and increase awareness among healthcare workers and their employers about the risks associated with working with hazardous drugs, and to provide them with additional measures to improve safety.

Material and methods The assessment of surface contamination with cytotoxic drugs was done by evaluating wipe samples collected from four comparable surfaces on the wards (work benches, floors, armrest of patient's chair and lids of waste containers). Each sample was analysed for the presence of five commonly used cytotoxic drugs (cyclophosphamide, 5-fluorouracil, paclitaxel, gemcitabine and total platinum for platinum drugs), using ICP-MS for total platinum and LC-MS/MS for other substances.

Results The database includes results collected from 28 hospital units from 16 European countries. Of the 560 samples collected, 268 were positive (48\%). Measurable amounts of at least one substance were detected on investigated surfaces in every hospital: 21/28 (75\%) hospitals had over 30\% positive samples. Contamination was detected mostly on the floors (58\%), armrests (50\%), lids (42\%) and work benches $(40 \%)$. The highest values were found for cyclophosphamide $\left(380 \mathrm{ng} / \mathrm{cm}^{2}\right)$ and 5 -fluorouracil $\left(130 \mathrm{ng} / \mathrm{cm}^{2}\right)$ on the lids. The highest number of positive results were recorded with platinum drugs (33\%), 5-fluorouracil (25\%), gemcitabine (19\%) and cyclophosphamide (18\%). Substances were detected on $45 / 112$ of surfaces (40\%) which had not been used for cytotoxic drug preparation on the day of the wipe sampling.

Conclusion and relevance Contamination is detectable on the ward but at different levels in different hospitals. Cleaning procedures are still not effective. Therefore, evaluation of exposure of healthcare workers is crucial. Greater collaboration with medical and nurse societies, to improve safe handling procedures in hospitals and thus improve the safety of all healthcare workers, is required.
REFERENCES AND/OR ACKNOWLEDGEMENTS

No conflict of interest.

\section{PC-042 THE SIGNIFICANCE OF PHARMACY PREPARATION IN PAEDIATRICS: MAKING INDIVIDUAL THERAPIES FOR CRITICALLY ILL CHILDREN POSSIBLE}

B Verdino*, K Nemec. Donauspital, Hospital Pharmacy, Vienna, Austria

\subsection{6/ejhpharm-2020-eahpconf.89}

Background and importance The 1000 bed Donauspital, Vienna, provides all types of care for children, including a paediatric intensive care unit (PICU) and a neonatal intensive care unit (NICU). Pharmacotherapy in paediatrics is often limited because no licensed medication is available for the condition of the child or, if available, the dosage is not correct for age and/or developmental stage. Therefore, individually manufactured medicines play an important role in the therapy of children.

As we had to assess the appropriateness of our allocation of human resources, we conducted this study to find out what amount of manufactured medicines are needed to treat our paediatric patients.

Aim and objectives We investigated the extent of individually manufactured medications for children in our hospital (figure 1). These medications included all types of dosage forms (eg, capsules, suppositories, intravenous preparations and compounded solutions for parenteral nutrition (TPN)) to see if drug therapy in critically ill children can be successful without manufacturing in the pharmacy and to evaluate the significance of pharmacy production.

Material and methods For three months (May to July 2019) all prescriptions for patients in the PICU and NICU were recorded from the critical care information system of the hospital. We compared the number of individually manufactured medications with the number of drugs used that were commercially available. All drugs were counted once per used dosage, even when prescribed several times for the same patient. We also counted TPN only once per patient (one solution containing amino acids, electrolytes and trace elements and one lipid emulsion containing vitamins), although the amount of the components prescribed changed almost daily.

Results During our study period in both the PICU and NICU, 99 children were hospitalised and treated with 1286

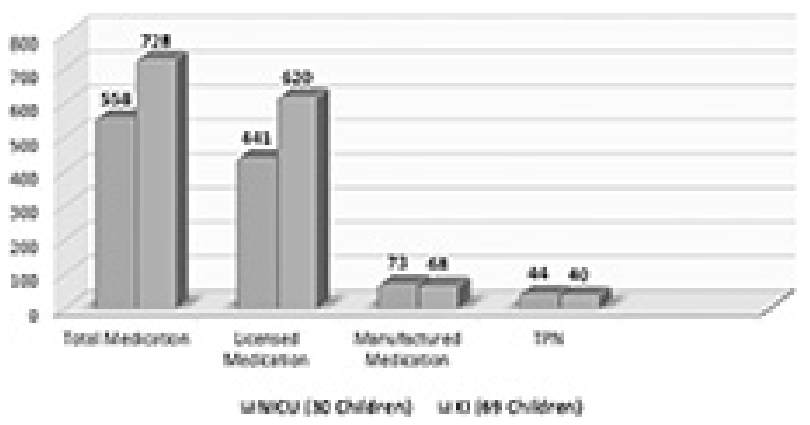

Abstract 3PC-042 Figure 1 Comparison of individually manufactured and commercially available medications used in the NICU and PICU 